\title{
Novel UV-emitting single crystalline film phosphors grown by LPE method
}

\author{
Y. Zorenko ${ }^{\mathrm{a}, *}$, V. Gorbenko ${ }^{\mathrm{a}}$, V. Savchyn ${ }^{\mathrm{a}}$, T. Voznyak ${ }^{\mathrm{a}}$, M. Nikl $^{\mathrm{b}}$, J.A. Mares $^{\mathrm{b}}$, A. Winnacker ${ }^{\mathrm{c}}$ \\ ${ }^{a}$ Laboratory of optoelectronic materials, Department of Electronic, Ivan Franko National University of Lviv, Gen. Tarnavsky 107,79017 Lviv, Ukraine \\ ${ }^{\mathrm{b}}$ Institute of Physics AS CR, Cukrovarnicka 10, 16253 Prague, Czech Republic \\ ${ }^{\mathrm{c}}$ Department of Materials Science, University of Erlangen-Nuremberg, Martensstrasse 8, D-91058 Erlangen, Germany
}

\section{A R T I C L E I N F O}

\section{Article history:}

Received 12 August 2009

Received in revised form

29 September 2009

Accepted 15 October 2009

\section{Keywords:}

UV luminescence

Single crystalline film

Liquid phase epitaxy

Garnets and perovskites

$\mathrm{Ce}^{3+}$

$\mathrm{Pr}^{3+}$

$\mathrm{La}^{3+}$

$\mathrm{Sc}^{3+}$

$\mathrm{Bi}^{3+}$ dopants

\begin{abstract}
A B S T R A C T
This work reports the development of new types of UV-emitting phosphors based on single crystalline films (SCF) of aluminum garnet and perovskite compounds grown by the liquid phase epitaxy method. We consider peculiarities of the growth and the luminescent and scintillation properties of the following four types of UV SCF phosphors: i) Ce-doped SCF of Y-Lu-Al-perovskites with the $\mathrm{Ce}^{3+}$ emission in the $300-450 \mathrm{~nm}$ range of the decay time of 16-17 ns; ii) Pr-doped SCF of Y-Lu-Al garnets and perovskites with the $\mathrm{Pr}^{3+}$ emission in the $300-400 \mathrm{~nm}$ and $235-330 \mathrm{~nm}$ ranges with the decay time of 13-19 and 7-8 ns, respectively; iii) $\mathrm{La}^{3+}$ or $\mathrm{Sc}^{3+}$ doped SCF of Y-Lu-Al-garnets, emitting in the $280-400 \mathrm{~nm}$ range due to formation of the $\mathrm{La}_{Y, \mathrm{Lu}}, \mathrm{SC}_{Y, \mathrm{Lu}}$ and $\mathrm{Sc}_{\mathrm{Al}}$ centers with decay time of the order of several hundreds of nanoseconds; iv) $\mathrm{Bi}^{3+}$ doped SCF of garnets with $\mathrm{Bi}^{3+}$ emission in $275-350 \mathrm{~nm}$ with decay time of about $1.9 \mu \mathrm{s}$.
\end{abstract}

(c) 2009 Elsevier Ltd. All rights reserved.

\section{Introduction}

The liquid phase epitaxy (LPE) for the last three decades shows itself as a beneficial method for the development of phosphors based on single crystalline films (SCF) of oxide compounds (Robertson and van Tol, 1984; Ferrand, et al., 1999; Zorenko, et al., 1990, 2002, 2003, 2009a,b; Zorenko and Gorbenko, 2009; Kucera et al., 2008). The application fields of such SCF phosphors now include the $\alpha$ - and $\beta$-scintillators, screens for visualization of X-ray images and cathodoluminescent (CL) screens, thermoluminescent media and luminescent converters of LED (Zorenko, et al., 2005).

In this work, we focus on creation of the UV-emitting SCF phosphors based on garnet and perovskite compounds. The reasons for the development of such phosphors are as follows:

1. Shift of the emission spectra of SCF scintillators into the UV range with respect to recently developed SCFs of $\mathrm{Ce}^{3+}$-doped $\mathrm{Y}_{3} \mathrm{Al}_{5} \mathrm{O}_{12}$ (YAG) and $\mathrm{Lu}_{3} \mathrm{Al}_{5} \mathrm{O}_{12}$ (LuAG) garnets, emitting in the visible range (Zorenko, et al., 2007a), in principle, can result in the faster emission decay, larger light yield (LY) and higher energy resolution. Namely, we try to extend the class of novel

\footnotetext{
* Corresponding author.

E-mail address: zorenko@electronics.wups.lviv.ua (Y. Zorenko).
}

UV-emitting SCF scintillators with the Ce-doped $\mathrm{YAlO}_{3}$ (YAP) and $\mathrm{LuAlO}_{3}$ (LuAP) perovskites and $\mathrm{Pr}^{3+}$-doped garnets and perovskites.

2. Future development of raster scanning optical microscopes equipped by electron-beam tubes with SCF screens as CL light sources (Hrytskiv, et al., 2007) requires the creation of SCF screens emitting in the selected ranges from 400 to $230 \mathrm{~nm}$. Specificaly, using the UV-emitting CL-excited light sources gives the possibility for analysis of biological objects in such microscope under the UV light.

3. Microimaging techniques with X-ray or synchrotron radiation (SR) for applications in microtomography and industry demand for the fast detectors of X-ray images, based on the SCF scintillating screens and microscope optics, with spatial resolution in the $\mu \mathrm{m}$-sub- $\mu \mathrm{m}$ range (Koch, et al., 1999; Martin and Koch, 2006). Future increase of the spatial resolution of such detectors according to the formula: $0.61^{*} \lambda / \mathrm{NA}$, where $\lambda$ is the emission wavelength and NA is the numerical aperture of the optics, requires creation of SCF screens emitting in the UV range. For visualization of X-ray images through the UV light we try to develop the novel SCF scintillating screens based on LuAG and LuAP compounds with significantly higher density $(\rho=6.67$ and $\left.8.34 \mathrm{~g} / \mathrm{cm}^{3}\right)$ and effective atomic number $\left(Z_{\mathrm{eff}}=59\right.$ and 62$)$ (Zorenko et al., 2002) as compared to commonly used YAG $\left(\rho=4.6 \mathrm{~g} / \mathrm{cm}^{3}, Z_{\text {eff }}=29\right.$ ) (Koch, et al., 1999). To obtain the 
intense UV scintillation, the $\mathrm{Pr}^{3+}, \mathrm{La}^{3+}$ and $\mathrm{Sc}^{3+}$ ions can be used as activators in LuAG SCF and $\mathrm{Ce}^{3+}$ and $\mathrm{Pr}^{3+}$ ions LuAP SCF.

In this work, we have briefly analyzed peculiarities of the growth and the luminescent and scintillation properties of several types of UV-emitting LPE-grown SCF phosphors.

\section{Growth of SCF phosphors and experimental techniques}

The series of Pr, La, Sc and Bi-doped YAG and LuAG and Ce or Prdoped YAP and LuAP SCF phosphors were grown in University of Lviv by the LPE methods onto YAG and YAP substrates, respectively, with the melt-solution (MS) based on the $\mathrm{PbO}-\mathrm{B}_{2} \mathrm{O}_{3}$ flux at relatively low $\left(950-1100{ }^{\circ} \mathrm{C}\right)$ temperatures as compared to Czochralskigrown single crystal (SC) analogues $\left(\sim 2000^{\circ} \mathrm{C}\right)$. For the growth of YAP:Ce SCF onto YAP substrates we also used the novel lead-free $\mathrm{BaO}-\mathrm{BaF}_{2}-\mathrm{B}_{2} \mathrm{O}_{3}$ flux. The Bi-doped YAG and LuAG SCF were grown on YAG substrates using the $\mathrm{Bi}_{2} \mathrm{O}_{3}$ flux. The concentration of $\mathrm{Bi}^{3+}$ ions in these SCFs was varied by the change of growth temperature in the 0.05-0.18 and 0.13-0.57 at. \% ranges, respectively. The thickness of the SCF phosphors was in the 4.8-45 $\mu \mathrm{m}$ range.

The content of different dopants in SCF was determined using a JEOL JXA-8612 MX electron microscope and is presented in Table 1 for different series of SCF phosphors.

Lower growth temperature of SCFs of garnets and perovskites results in the absence of the $\mathrm{Y}_{\mathrm{Al}}$ and $\mathrm{Lu}_{\mathrm{Al}}$ antisite defects (AD) and decrease of the content of other type of defects in SCF in comparison with bulk SC analogues (Zorenko, et al., 2007a,b). On the other hand, flux components can be introduced in the SCF and can influence their emission and scintillation properties. We have shown recently that the YAG:Ce and LuAG:Ce SCFs grown from the $\mathrm{PbO}$-based flux usually contain lead ion contamination preferably in the $\mathrm{Pb}^{2+}$ charge state. It causes decrease of the LY and slowingdown the scintillation response (Babin, et al., 2007; 2009a,b). Therefore, LY of UV-emitting SCF phosphors can also strongly depend on the activator concentration and $\mathrm{Pb}^{2+}$ contamination level.

Due to significant difference in the segregation coefficient of the La, Sc and Pr ions in YAG and LuAG SCF grown on YAG substrates and $\mathrm{Ce}$ and Pr ions in YAP and LuAP SCF, grown on YAP substrates (Zorenko, et al., 2003, 2009a), the content of $\mathrm{Sc}_{2} \mathrm{O}_{3}, \mathrm{La}_{2} \mathrm{O}_{3}, \mathrm{Pr}_{2} \mathrm{O}_{3}$ oxides in MS was varied in the 2.25-6.7; $1.0-8.2$, 3.1-8.6 mole \% ranges, respectively, for $\mathrm{SCF}$ of garnets, and $\mathrm{CeO}_{2}$ and $\mathrm{Pr}_{2} \mathrm{O}_{3}$ oxides in 2.0-20 and 1.0-10.5 mole \% ranges, respectively, for SCF of perovskites. The concentration of these dopants in the SCF depends not only on the content of activated oxides in MS, but is also strongly influenced by the SCF growth temperature. Usually the activators/Pb ratio increase with increasing the growth temperature and vice versa. Thus we have used relatively high temperatures above $950^{\circ} \mathrm{C}$ for the SCF growth.

The CL spectra of SCF phosphors were measured at $300 \mathrm{~K}$ with a set-up based on a DMR-4 monochromator and a FEU-106 PMT under pulsed e-beam excitation $(9 \mathrm{KeV}, 100 \mu \mathrm{A})$ with pulse duration of $2 \mu \mathrm{s}$ and a frequency of $3-30 \mathrm{~Hz}$.

The decay of luminescence was measured at $300 \mathrm{~K}$ in the time interval 0-200 ns under excitation by SR with pulse duration of $0.126 \mathrm{~ns}$ at Superlumi station (HASYLAB, DESY). Decay curves of $\mathrm{Bi}^{3+}$ luminescence were measured by $199 \mathrm{~S}$ Spectrofluorometer (Edinburgh Instrument) equipped by TBX-04 PMT detection modul (IBH Scotland) under the excitation by nanosecond coaxial hydrogen-filled flashlamp 5000F.

Relative LY of all the mentioned SCF phosphors was measured in comparison with that of the corresponding samples of YAG:Pr, LuAG:Pr, YAG:La, YAG:Sc, LuAG:Sc, YAP:Ce and $\mathrm{Lu}_{0.3} \mathrm{Y}_{0.7} \mathrm{AG}$ :Ce bulk SCs under the excitation by $\alpha$-particles of $\mathrm{Am}^{241}(5.5 \mathrm{MeV})$ sources
Table 1

Relative LY of the best samples in series of UV-emitting SCF phosphors in comparison with their bulk SC analogues under excitation by $\alpha$-particles of $\mathrm{Am}^{241}$ (5.49 MeV) sources (A- activator content; $\lambda_{\max },-$ maximum of emission band; $\tau$ - decay time of emission).

\begin{tabular}{|c|c|c|c|c|c|}
\hline Dopant & Phosphors & A, at.\% & $\lambda_{\max }, \mathrm{nm}$ & $\tau, \mathrm{ns}$ & $\mathrm{LY}, \%$ \\
\hline \multirow[t]{6}{*}{$\mathrm{Ce}$} & YAP:Ce SCF (PbO flux) & 0.08 & 366 & 13.1 & 36.1 \\
\hline & YAP:Ce SCF (BaO flux) & 0.053 & 373 & 16.1 & 33.7 \\
\hline & $\mathrm{Y}_{0.4} \mathrm{Lu}_{0.6} \mathrm{AP}: \mathrm{Ce} \mathrm{SCF}$ (PbO flux) & $\sim 0.04$ & 363 & 16.0 & 14.4 \\
\hline & LuAP:Ce SCF (PbO flux) & 0.013 & 358 & 16.9 & 10.8 \\
\hline & YAP:Ce SC & $\sim 0.1$ & 366 & 16.2 & 100 \\
\hline & $\mathrm{Lu}_{0.3} \mathrm{Y}_{0.7} \mathrm{AG}: \mathrm{Ce} \mathrm{SC}$ & $\sim 0.1$ & 375 & 17.1 & 83.2 \\
\hline \multirow[t]{7}{*}{$\operatorname{Pr}$} & YAG:Pr SCF & 0.085 & 323 & 12.5 & 33.7 \\
\hline & LuAG:Pr SCF & 0.66 & 305 & 18.5 & 29.8 \\
\hline & YAG:Pr SC & 0.19 & 327 & 17.6 & 75.4 \\
\hline & LuAG:Pr SC & 0.31 & 308 & 18.6 & 59.3 \\
\hline & YAP:Pr SCF & $\sim 0.08$ & 250 & 8.1 & 10 \\
\hline & LuAP:Pr SCF & $\sim 0.07$ & 240 & 7.8 & 15 \\
\hline & YAP:Pr SC & $\sim 0.1$ & 250 & 8.0 & 22.7 \\
\hline \multirow[t]{3}{*}{$\mathrm{La}$} & YAG:La SCF & 0.045 & 297 & 290 & 13.6 \\
\hline & LuYAG:La SCF & 0.04 & 282 & 170 & 15.9 \\
\hline & YAG:La SC & 0.085 & 298 & 575 & 30.3 \\
\hline \multirow[t]{6}{*}{ Sc } & $\mathrm{Y}_{2.96} \mathrm{Sc}_{0.475} \mathrm{Al}_{4.555} \mathrm{O}_{12} \mathrm{SCF}$ & 2.38 & $\begin{array}{l}303 ; \\
329\end{array}$ & $\sim 750$ & 38.7 \\
\hline & $\mathrm{Y}_{2.84} \mathrm{Lu}_{0.14} \mathrm{Sc}_{0.37} \mathrm{Al}_{4.65} \mathrm{O}_{12} \mathrm{SCF}$ & 1.85 & 298 & $\sim 650$ & 57.5 \\
\hline & $\mathrm{Y}_{2.76} \mathrm{Lu}_{0.18} \mathrm{Sc}_{0.715} \mathrm{Ga}_{0.09} 5 \mathrm{Al}_{4.25} \mathrm{O}_{12} \mathrm{SCF}$ & 3.60 & 325 & $\sim 800$ & 28.0 \\
\hline & $\mathrm{Lu}_{2.92} \mathrm{Sc}_{0.18} \mathrm{Al}_{4.9} \mathrm{O}_{12} \mathrm{SCF}$ & 0.9 & 292 & $\begin{array}{l}245 \\
415\end{array}$ & 48.5 \\
\hline & $\mathrm{Y}_{2.995} \mathrm{Sc}_{0.077} \mathrm{Al}_{4.864} \mathrm{O}_{12} \mathrm{SC}$ & 0.39 & 290 & $\sim 580$ & 69.3 \\
\hline & $\mathrm{Lu}_{2.77} 3 \mathrm{Sc}_{0.022} \mathrm{Al}_{5.205} \mathrm{O}_{12} \mathrm{SC}$ & 0.11 & 275 & 1330 & 31.4 \\
\hline \multirow[t]{2}{*}{$\mathrm{Bi}$} & YAG:Bi & 0.13 & 303 & 1930 & 20.6 \\
\hline & LuAG:Bi & 0.18 & 298 & 1840 & 15.1 \\
\hline
\end{tabular}

using detector based on hybrid DEP PPO 475B PMT with the maximum sensitivity in the $200-400 \mathrm{~nm}$ range and multichannel analyzer working with shaping time of $3 \mu \mathrm{s}$. The results of LY measurements are shown in Table 1.

\section{Luminescence spectra and LY of SCF phosphors}

\subsection{Ce-doped perovskites}

The CL spectra of YAP:Ce and LuAP:Ce SCF (Fig. 1) show the intensive emission band in the UV $(320-450 \mathrm{~nm})$ range related to the $5 \mathrm{~d} \rightarrow 4 \mathrm{f}$ transitions of $\mathrm{Ce}^{3+}$ ions. The short-wavelength part of the $\mathrm{Ce}^{3+}$ emission band in these SCFs grown from the PbO-based flux (labeled later as (Y,Lu)AP:Ce (PbO) SCFs) is strongly distorted by the UV emission band of $\mathrm{Pb}^{2+}$ ions peaked at $340 \mathrm{~nm}$ (Babin, et al., 2009a,b) (Fig. 1). This caused a short-wavelength shift of the emission spectrum of YAP:Ce (PbO) SCF (Fig. 1, curve 2) with respect to the spectrum of the same SCF grown from the lead-free BaO-based flux (labeled later as YAP:Ce (BaO) SCF) (Fig. 1, curve 1).

The LY of best samples of YAP:Ce and LuAP:Ce SCF is significantly lower (by 3.9 and 7.6 times, respectively) than that of their YAP:Ce and (Y-Lu)AP:Ce SC analogues (Table 1). The main reason for such a low LY of these SCFs is the large incorporation of $\mathrm{Pb}^{2+}$ ions in SCF of perovskites in comparison with SCF of garnets (Zorenko and Gorbenko, 2009; ) due to larger volume of cuboctahedral position in perovskite lattice with respect to the dodecahedral sites of garnet host, where $\mathrm{Pb}^{2+}$ ions are localized. We also note that the LY of (YLu)AP:Ce SCF systematically decrease with rising the Lu content up to a value of $10.8 \%$ for LuAP:Ce SCF as compared to that of YAP:Ce SC. This effect is caused by the large content of $\mathrm{Pb}^{2+}$ ions in LuAPbased SCF with respect to YAP SCF due to preferable $\mathrm{Lu}-\mathrm{Pb}$ pair incorporation in comparison with $\mathrm{Y}-\mathrm{Pb}$ pair in the case of SCF growth of both types of perovskites on YAP substrates (Zorenko and Gorbenko, 2009). 


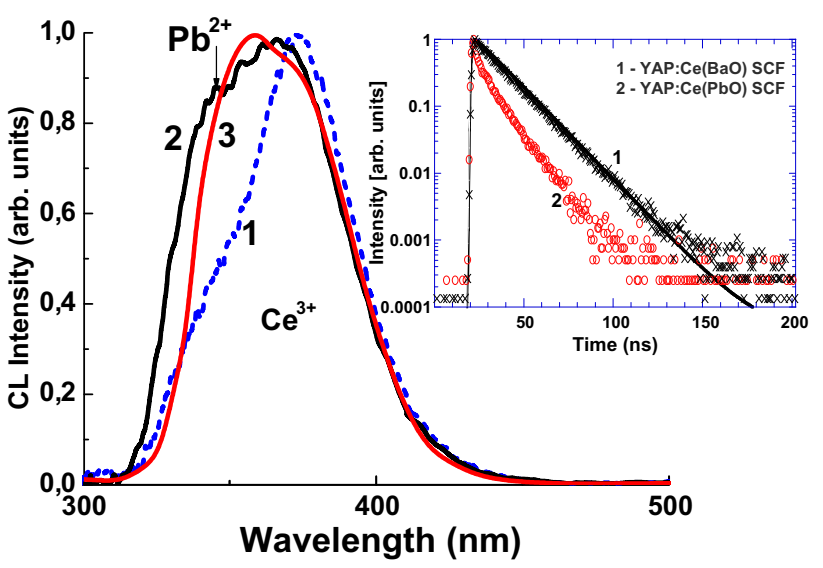

Fig. 1. CL spectra (normalized) of YAP:Ce $(1,2)$ and LuAP:Ce (3) SCF at $300 \mathrm{~K}$ grown from the $\mathrm{BaO}(1)$ and $\mathrm{PbO}(2,3)$ based fluxes; insert - decay kinetics of $\mathrm{Ce}^{3+}$ luminescence in YAP:Ce (BaO) (1) and YAP (PbO) (2) SCF under excitation in $\mathrm{Ce}^{3+}$ absorption band at $300 \mathrm{~nm}$.

The decay curve of $\mathrm{Ce}^{3+}$ emission in YAP:Ce (PbO) SCF is strongly non-exponential (inset of Fig. 1, curve 2) and is characterized by the mean decay time of $13.1 \mathrm{~ns}$ (Table 1 ). Such a shortening the decay time of the $\mathrm{Ce}^{3+}$ emission in YAP:Ce (PbO) SCF, can be caused by energy transfer from the $\mathrm{Ce}^{3+}$ ions to $\mathrm{Pb}^{2+}$-related centers with the excitation bands in the 350-370 nm range which overlap with the $\mathrm{Ce}^{3+}$ emission band (Babin, et al., 2009a,b). From the calculation of the integral of the normalized decay curves for YAP:Ce (PbO) and YAP:Ce (BaO) SCFs (inset of Fig. 1), we estimate that in the former SCF the losses of more than $50 \%$ of energy take place due to energy transfer from the $\mathrm{Ce}^{3+}$ ions to $\mathrm{Pb}^{2+}$-based centers. Such large losses can partly explain very low LY of YAP:Ce (PbO) and LuAG:Pr (PbO) SCF (Table 1). Contrary to these SCFs, the $\mathrm{Ce}^{3+}$ emission decay in YAP:Ce (BaO) SCF is single-exponential (inset of Fig. 1, curve 2) with the decay time of $16 \mathrm{~ns}$ which is close to the decay time of the $\mathrm{Ce}^{3+}$ emission in YAP:Ce SC (Table 1). That reflects the great application potential of BaO-based fluxes for growth of SCF phosphors. However, the main problem of using the $\mathrm{BaO}$-based flux is its high viscosity and surface tension. Low SCF growth rate resulted in worse surface morphology and uniformity of SCF properties (Zorenko, et al., 2009a). We also did not succeed with the heteroepitaxial crystallization of LuAG and LuAP SCFs on cheaper YAG and YAP substrates using the BaO-based flux.

\section{2. $\mathrm{Pr}^{3+}$-doped garnets and perovskites}

The CL spectra of YAG:Pr and LuAG:Pr SCFs showed intensive and fast emission in the $290-450 \mathrm{~nm}$ range with the main maxima at 323 and $305 \mathrm{~nm}$, with the decay time of about 13 and $19 \mathrm{~ns}$, respectively, caused by the $5 \mathrm{~d}^{1} 4 \mathrm{f}^{1} \rightarrow 4 \mathrm{f}^{2}\left({ }^{3} \mathrm{H}_{4},{ }^{3} \mathrm{H}_{5},{ }^{3} \mathrm{H}_{6},{ }^{3} \mathrm{~F}_{3(4)}\right)$ transition of $\mathrm{Pr}^{3+}$ ions (Fig. 2) (Pejchal, et al., 2009). The same transitions in YAP:Pr and LuAP:Pr SCFs yield even faster emission in the $235-325 \mathrm{~nm}$ range with the maximum at 240 and $250 \mathrm{~nm}$, respectively, and decay time of about 8 ns for both SCF (Fig. 2b) (Zhuravleva, et al., 2007).

The detailed consideration of luminescent properties of $\mathrm{Pr}^{3+}$ doped (YLu)AG and (Y,Lu)AP SCF is given in (Gorbenko et al., in this issue). Here we mentione only that the LY of (Y,Lu)AG:Pr and (Y,Lu)AP:Pr SCFs is significantly lower (by 2.2-2.8 times) than that of their SC analogues (Table 1 ). The main reason for such low LY of the $\mathrm{Pr}^{3+}$-doped. SCF of garnets and perovskites is the strong quenching influence of the $\mathrm{Pb}^{2+}$ flux impurity. From the results presented in Table 1, we conclude that significantly larger influence

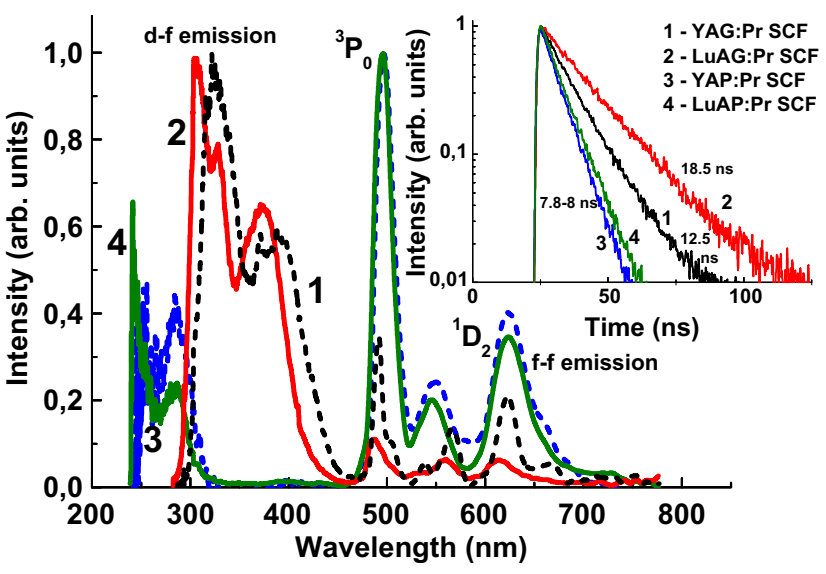

Fig. 2. CL spectra and decay kinetics (inset) of $\mathrm{Pr}^{3+}$ luminescence in YAG:Pr (1), LuAG:Pr (2), YAP:Pr (3) and LuAP:Pr (4) SCF at $300 \mathrm{~K}$.

of $\mathrm{Pb}^{2+}$ ions on the UV emission of $\mathrm{Pr}^{3+}$ ions takes place in (Y,Lu)AG:Pr and (Y,Lu)AP:Pr SCFs in comparison with the influence of such impurity on the $\mathrm{Ce}^{3+}$ emission in the visible range in SCF of Ce-doped garnets (Zorenko, et al., 2007a). The mechanism of the $\mathrm{Pb}^{2+} \rightarrow \mathrm{Pr}^{3+}$ energy transfer in Pr-doped SCF of garnets is considered by Gorbenko et al., 2009.

\subsection{La-doped garnets}

The CL spectra of YAG:La and LuAG:La SCFs are shown in Fig. 3a. The intensive complex emission bands in the $250-450 \mathrm{~nm}$ range are caused by the $\mathrm{La}^{3+}$ isoelectronic impurity and present superposition of two closely-lying bands peaked at 298, $305 \mathrm{~nm}$ and 267 , $282 \mathrm{~nm}$ (curve 1 and 2, respectively), related to the luminescence of exciton localized around $\mathrm{La}_{\mathrm{Lu}, \mathrm{Y}}$ centers and recombination luminescence of $\mathrm{La}_{\mathrm{Y}}$ and $\mathrm{La}_{\mathrm{Lu}}$ centers, respectively (Zorenko, 2006). In (Y,Lu)AG:La SCFs, grown from PbO-based flux, the UV emission band of $\mathrm{Pb}^{2+}$ ions peaked at $350-360 \mathrm{~nm}$ is also observed (Fig. 3a).

The decay kinetics of the $\mathrm{La}_{\mathrm{Y}}$ and $\mathrm{La}_{\mathrm{Lu}}$ centers emission in YAG:La and LuAG:La SCFs under excitation in the exciton range with energy of 6.52 and $6.88 \mathrm{eV}$, respectively, is shown in Fig. 3c. The decay time of main components of $\mathrm{La}_{\mathrm{Y}}$ and $\mathrm{La}_{\mathrm{Lu}}$ centers luminescence is 560 and $170 \mathrm{~ns}$, respectively.

The LY of YAG:La and LuAG:La SCF significantly depends on the La content but is not so strongly influenced by the $\mathrm{Pb}^{2+}$ flux

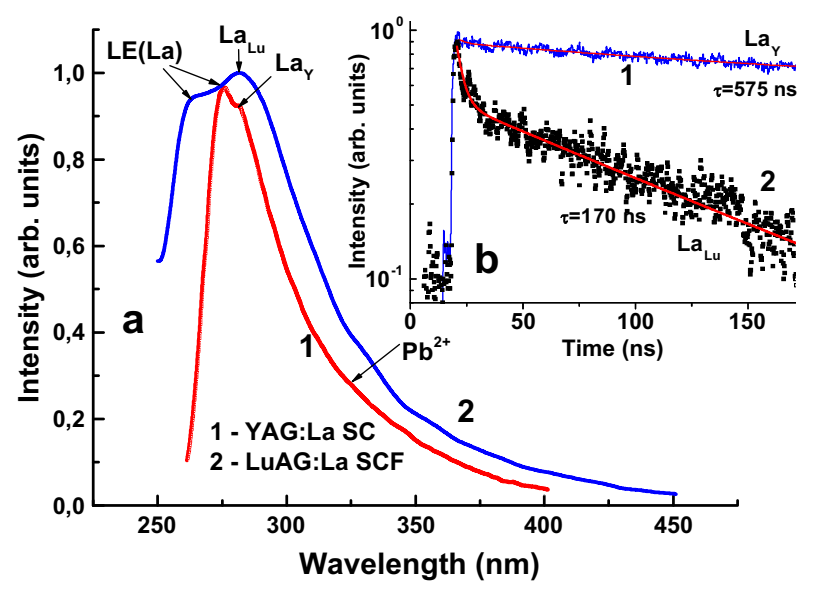

Fig. 3. a - CL spectra (a) and decay kinetic (b) of luminescence of $\mathrm{La}_{\mathrm{Y}}(1)$ and $\mathrm{La}_{\mathrm{Lu}}(2)$ centers at 290 and $285 \mathrm{~nm}$ in YAG:La (1) and LuAG:La (2) SCFs under excitation by SR at 6.52 and $6.88 \mathrm{eV}$, respectively. $T=300 \mathrm{~K}$. 

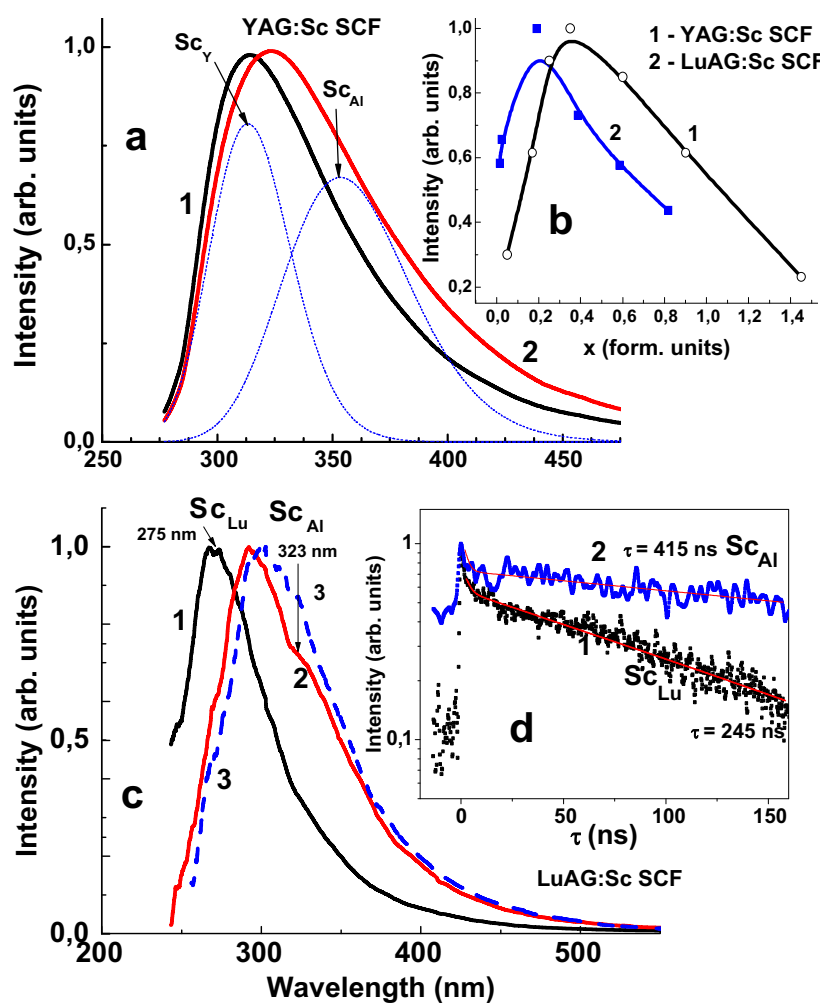

Fig. 4. Normalize CL spectra of YAG:Sc (a) and LuAG:Sc (c) SCF with Sc content of 1.8 (1a), 4.13 (2a), 0.12 (1c), 1.94 (2c) and 4.08 (3c) at.\%, respectively. Decomposition of spectrum 2 in Fig. 5a is given by dashed lines. (d) - dependence of integral intensity of CL on total scandium content in YAG:Sc (1) and LuAG:Sc (2) SCFs; (d) - decay kinetics of luminescence of $\mathrm{Sc}_{\mathrm{Lu}}$ (1) and $\mathrm{Sc}_{\mathrm{Al}}$ (2) centers at 280 (1) and $335 \mathrm{~nm}$ (2) in LuAG:Sc SCF under excitation by SR with an energy of $6.88 \mathrm{eV} . T=300 \mathrm{~K}$.

impurity. Namely, the LY of (Y,Lu)AG:La SCFs with La content of $0.04-0.05$ at. \% is by 2-3 times lower in comparison with YAG:La (0.085 at.\%) SC (Table 1 ). Also, the LY of these SCFs is significantly (by 2-4 times) lower than that of Sc-doped YLuAG and LuAG SCFs. Such a low LY of La-doped SCFs is mainly caused by very low (0.005) segregation coefficient of $\mathrm{La}^{3+}$ ions at the LPE-growth of YAG:La and LuAG:La SCFs in comparison with that (0.14) for YAG:La SC. As a result, rather small (0.04-0.045 at.\%) $\mathrm{La}^{3+}$ concentration can be achieved in these SCFs (Table 1) even at large (above 8 mole \%) content of $\mathrm{La}_{2} \mathrm{O}_{3}$ dopant in MS in comparison with an optimum value of 0.4-0.9 at.\% for Sc-doped SCF of these garnets (Table 1).

\subsection{Sc-doped garnets}

In contrast to $\mathrm{La}^{3+}$ ions, the $\mathrm{Sc}^{3+}$ isoelectronic impurity in YAG and LuAG SCFs has relatively high (0.8-0.55 and 0.4-0.2, respectively) segregation coefficient. This allows to readily achieving the optimum values of Sc doping in SCF of these garnets in the range $0.4-0.9$ at. \%, at which the highest LY of these SCFs is observed (Fig. 4b, Table 1).

The $\mathrm{Sc}^{3+}$ ions in YAG and LuAG SCF substituted both the dodecahedral $\{\mathbf{c}\}$ - and octahedral (a)- sites of garnet lattice and formed the $\mathrm{Sc}_{Y, \mathrm{Lu}}$ and $\mathrm{Sc}_{\mathrm{Al}}$ emission centers, respectively (Zorenko, 2006). Such distribution of $\mathrm{Sc}^{3+}$ ions over the $\{\mathbf{c}\}$ - and (a)-sites explains the dependence of the positions of emission bands of (Y,Lu)AG:Sc on the Sc content (Fig. 5b). At relatively small ( $\mathrm{x}=0.05-0.2$ formula units (f.u.)) Sc content, the bands at 313 and $275 \mathrm{~nm}$, respectively, dominates in the luminescence of YAG:Sc (Fig. 4a) and LuAG:Sc SCF (Fig. 4c). The bands at 353 and $323 \mathrm{~nm}$, become

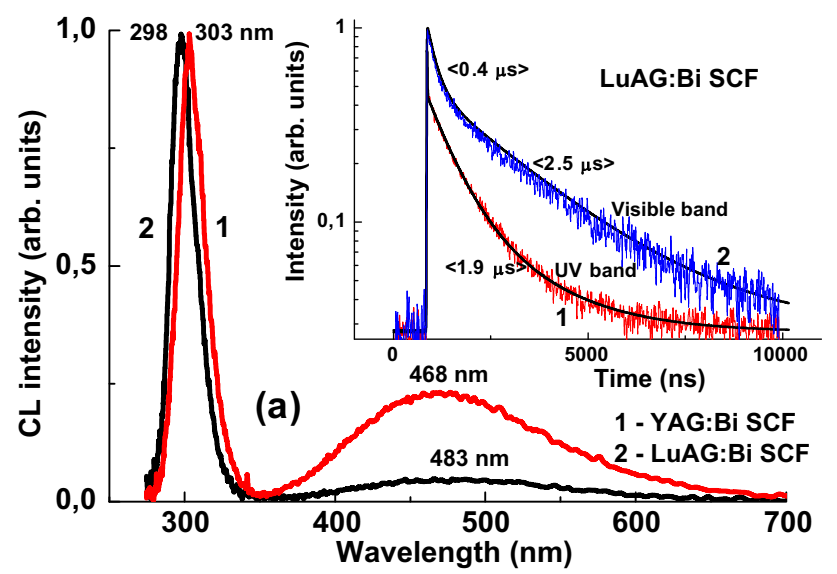

Fig. 5. a - CL spectra of LuAG:Bi and YAG:Bi SCF; b - decay kinetic of $\mathrm{Bi}^{3+}$ emission in UV (1) and visible (2) bands in LuAG:Bi SCF; $T=300 \mathrm{~K}$.

dominant at larger ( $x>0.2$ f.u.) Sc content (Fig. $4 a$ and $c$ ), which correlate with substantial increase of the LY of these SCF (Fig. 4b, Table 1). Maximum of the LY of YAG:Sc and LuAG:Sc SCF is reached at $\mathrm{x}=0.3-0.4$ f.u. (Fig. $4 \mathrm{~b}$ ). At the highest Sc content the decrease in the LY of SCs and SCFs (Fig. 4b) occurs due to the concentration quenching of the emission of $\mathrm{Sc}^{3+}$-related centers.

The luminescence decay kinetics of the $\mathrm{Sc}_{\mathrm{Y}, \mathrm{Lu}}$ and $\mathrm{Sc}_{\mathrm{Al}}$ centers is shown in Fig. 4d on the example of LuAG:Sc SCF. Under excitation with energy of $6.88 \mathrm{eV}$ in the exciton range the main components of the $\mathrm{Sc}_{\mathrm{Lu}}$ and $\mathrm{Sc}_{\mathrm{Al}}$ centers emission show the decay time of 245 and 415 ns (curve 1 and 2, respectively).

The LY of YAG:Sc and LuAG:Sc SCFs depends on the total Sc content and distribution of $\mathrm{Sc}^{3+}$ ions over the $\{\mathbf{c}\}$ - and (a)-sites of garnet host. The concentration of $\mathrm{Sc}_{\mathrm{Y}, \mathrm{Lu}}$ and $\mathrm{Sc}_{\mathrm{Al}}$ centers in these SCFs and their LY can be changed by substitution of host cations by other ions with smaller or larger dimensions. Namely, the $\mathrm{Lu}^{3+} \mathrm{CO}^{3}$ doping in $\{\mathbf{c}\}$-sites of $\mathrm{Y}^{3+}$ leads to increasing the LY of YAG:Sc SCF, whereas the $\mathrm{Ga}^{3+}$ co-doping in (a)-sites of $\mathrm{Al}^{3+}$ decrease the LY of these SCF (Table 1). The LY of (YLu)AG:Sc and LuAG:Sc SCFs at the optimal $\mathrm{Sc}^{3+}$ content $0.4-0.9$ f.u. is comparable with their SC analogues and reaches values of 57.5 and $47.5 \%$, respectively, of that for YAP:Ce SC (Table 1). This result shows that influence of $\mathrm{Pb}^{2+}$ dopant on the UV luminescence of $\mathrm{Sc}^{3+}$-based centers is not so much significant than that on the $\mathrm{Ce}^{3+}$ luminescence in SCF of perovskites and the $\mathrm{Pr}^{3+}$ luminescence in SCF of garnets. This allows the usage of PbO-based flux for the growth of UV-emitting SCF phosphors with relatively high LY.

\subsection{Bi-doped garnets}

For development of the UV-emitting SCF scintillators we also crystallized the $\mathrm{Bi}^{3+}$-doped YAG and LuAG SCFs by LPE method on YAG substrates (Zorenko, et al., 2009b). The concentration of $\mathrm{Bi}^{3+}$ ions in these SCF was varied in the range of $0.05-0.18$ at. \% by changing the growth temperature.

The CL spectra of YAG:Bi and LuAG:Bi SCFs (Fig. 5a) show the dominant band in UV range peaked at 303 and $298 \mathrm{~nm}$, respectively, related to ${ }^{3} \mathrm{P}_{1} \rightarrow{ }^{1} \mathrm{~S}_{0}$ radiative transitions of $\mathrm{Bi}^{3+}$ ions, and less intense visible one peaked in the $468-483 \mathrm{~nm}$ range caused by luminescence of localized excitons around $\mathrm{Bi}^{3+}$ single and dimer centers (Babin, et al., 2009b). The ratio of UV/blue emission bands can be tuned by the $\mathrm{Bi}^{3+}$ concentration: with increasing $\mathrm{Bi}^{3+}$ content in (Y,Lu)AG:Bi SCF the reduction of the intensity of UV emission band and relative increase of the intensity of visible band are observed. Decay time of the UV emission of $\mathrm{Bi}^{3+}$ ions in LuAG:Bi 
and YAG:Bi SCF at $300 \mathrm{~K}$ is about of $1.9 \mu \mathrm{s}$ (Fig. 5c, curve 1). The decay of visible emission is slower and can be fitted by the sum of two components with decay times of $0.2-0.4$ and $1.9-2.5 \mu \mathrm{s}$, related to luminescence of localized excitons around the $\mathrm{Bi}^{3+}$ single and dimer centers (Babin, et al., 2009b).

The LY of the LuAG:Bi and YAG:Bi SCFs reaches of about 15 and $21 \%$ of that of the YAP:Ce SC, respectively (Table 1). Therefore, these SCF can be proposed as scintillating screens for high-resolution X-ray imaging (Zorenko, et al., 2009b).

\section{Conclusions}

Development of four types of the UV-emitting single SCF phosphors grown by LPE methods is described in this work:

i) Ce-doped SCF of Y-Lu-Al-perovskites with $\mathrm{Ce}^{3+}$ emission in the 360-370 nm range with a decay time of 16-17 ns;

ii) Pr-doped SCF of Y-Lu-Al garnets and perovskites with $\mathrm{Pr}^{3+}$ emission in the $300-400 \mathrm{~nm}$ range with a decay time of 1319 ns and $\sim 8 \mathrm{~ns}$, respectively;

iii) La- and Sc-doped SCF of Y-Lu-Al-garnet compounds emitting in the $290-400 \mathrm{~nm}$ range due to formation of $\mathrm{La}_{Y, \mathrm{Lu}}$ or $\mathrm{Sc}_{\mathrm{Y}, \mathrm{Lu}}$ and $\mathrm{Sc}_{\mathrm{Al}}$ emission centers with the decay time of the luminescence in the several hundred ns range.

iv) $\mathrm{Bi}^{3+}$ doped SCF of garnets with $\mathrm{Bi}^{3+}$ emission in $275-350 \mathrm{~nm}$ with decay time of about $1.9 \mu \mathrm{s}$;

From all the above mentioned SCF phosphors the highest LY value is obtained at the (YLu)AG:Sc and LuAG:Sc SCF (45.5-57.5\%), followed by YAG:Pr and LuAG:Pr SCF (30-34\%) and YAP:Ce SCF (up to $36 \%$ ) in comparison with the LY of YAP:Ce reference crystal.

The main problem in the development of UV-emitting SCF phosphors by LPE method from the traditional $\mathrm{PbO}-\mathrm{B}_{2} \mathrm{O}_{3}$ flux consists in significantly larger influence of $\mathrm{Pb}^{2+}$ flux impurity on the UV luminescence of $\mathrm{Ce}^{3+}$ ions in SCF of perovskites and $\mathrm{Pr}^{3+}$ ions in SCF of garnets and perovskites with respect to recently developed YAG:Ce and LuAG:Ce SCF phosphors emitting in the visible range. This is the main reason for lower (by 2-3 times) LY of Pr-doped (Y-Lu)AG and (Y-Lu)AP SCFs and significantly lower (by 3.6-6 times) LY of Ce-doped YAP and LuAP SCFs in comparison with their SC analogues. Therefore, the future development of UVemitting phosphors based on the $\mathrm{Ce}^{3+}$ and $\mathrm{Pr}^{3+}$ doped SCF of perovskites and $\mathrm{Pr}^{3+}$ doped SCF of garnets strongly demands the use of alternative lead-free fluxes for their growth.

No such negative influence is observed in the Sc and La-doped SCF of Y-Lu-garnets which allow using the PbO-based flux for producing the UV-emitting SCF phosphors with high LY.

\section{Acknowledgements}

This work was supported by the projects of Ukrainian Ministry of Education and Science SF-28F and DZ-286-2008 and the project of Czech Science Foundation 202/08/0893.

\section{References}

Babin, V., Gorbenko, V., Makhov, A., Mares, J.A., Nikl, M., Zazubovich, S., Zorenko, Yu, 2007. Luminescence characteristics of $\mathrm{Pb}^{2+}$ centers in undoped and $\mathrm{Ce}^{3+}$-doped
$\mathrm{Lu}_{3} \mathrm{Al}_{5} \mathrm{O}_{12}$ single crystalline films and $\mathrm{Pb}^{2+\circledR} \mathrm{Ce}^{3+}$ energy transfer processes J. Lumin. 127, 384-390.

Babin, V., Bichevin, V., Gorbenko, V., Krasnikov, A., Makhov, A., Mihokova, E., Nikl, M., Vedda, A., Zazubovich, S., Zorenko, Yu, 2009a. Luminescence of dimer lead centers in aluminium perovskites and garnets. Phys. Stat. Sol. (b) 246 , 1318-1326.

Babin, V., Gorbenko, V., Krasnikov, A., Makhov, A., Nikl, M., Polak, K. ZazubovichZorenkoYu, S., 2009b. Peculiarities of excited state structure and photoluminescence in $\mathrm{Bi}^{3+}$-doped $\mathrm{Lu}_{3} \mathrm{Al}_{5} \mathrm{O}_{12}$ single crystalline films. J. Phys. Condens. Matter 21, 415502.

Ferrand, B., Chambaz, B., Couchaud, M., 1999. Liquid phase epitaxy: a versatile technique for the development of miniature optical components in single crystal dielectric media. Opt. Mater. 1, 101-114.

Gorbenko, V., Zorenko, Yu., Savchyn, V., Pedan A., Shkliarskyi, V. Growth and luminescence properties of $\mathrm{Pr}^{3+}$-doped single crystalline films of garnets and perovskites. Radiat. Meas., in this issue RADMEAS-D-09-00329.

Gorbenko, V., Krasnikov, A., Nikl, M., Zazubovich, S., Zorenko, Yu, 2009. Luminescence characteristics of LuAG: Pr and YAG: Pr single crystalline films. Opt. Mater.. doi:10.1016/j.optmat.2008.11.030.

Hrytskiv, Z., Zorenko, Y., Gorbenko, V., Pedan, A., Shkliarskyi, V., 2007. Single crystalline film screens for cathode-ray tubes: new life of television scanning optical microscopy. Radiat. Meas. 42, 933-936.

Koch, A., Peyrin, F., Heurtier, P., Chambaz, B., Ferrand, B., Ludwig, W., Couchaud, M. 1999. An X-ray camera for computed microtomography of biological samples with micrometer resolution using $\mathrm{Lu}_{3} \mathrm{Al}_{5} \mathrm{O}_{12}$ and $\mathrm{Y}_{3} \mathrm{Al}_{5} \mathrm{O}_{12}$ scintillators. Proc. SPIE 3659, 170-179.

Kucera, M., Nitsch, K., Kubova, M., Solovieva, N., Nikl, M., Mares, J.A., 2008. Ce-doped YAG and LuAG epitaxial films for scintillation detectors. IEEE Trans. Nucl. Sci. 55, 1201-1205.

Martin, T., Koch, A., 2006. Recent development in X-ray imaging with micrometer spatial resolution. J. Synchrotron Radiat. 13, 180-194.

Pejchal, J., Nikl, M., Mihóková, E., Mareš, J.A., Yoshikawa, A., Ogino, H., Schillemat, K.M., Krasnikov, A., Vedda, A., Nejezchleb, K., Múčka, V., 2009. Pr $^{3+}$ doped complex oxide single crystal scintillators. J. Phys. D: Appl. Phys. 42 055117-055127.

Robertsonvan Tol, J.M., van Tol, M.V., 1984. Cathodoluminescent garnet layers. Thin Solid Films 114, 221-240.

Zhuravleva, M., Novoselov, A., Yoshikawa, A., Pejchal, J., Nikl, M., Fukuda, T., 2007. Crystal growth and scintillation properties of Pr-doped $\mathrm{YAlO}_{3}$. Opt. Mater. 30 171-173.

Zorenko, Yu., Novosad, S., Pashkovskii, M., Lyskovich, A., Savitskii, V., Batenchuk, M. Malyutenkov, P., Patsagan, N., Nazar, I., Gorbenko, V., 1990. Epitaxial structures of garnets as scintillation detectors of ionizing radiation. J. Appl. Spectrosc. 52 645-649.

Zorenko, Yu., Gorbenko, V., Konstankevych, I., Grinev, B., Globus, M., 2002. Scintillation properties of $\mathrm{Lu}_{3} \mathrm{Al}_{5} \mathrm{O}_{12}$ :Ce single crystalline films. Nucl. Instrum. Methods Phys. Res. A486, 309-314.

Zorenko., Yu, Gorbenko, V., Konstankevych, I., 2003. Peculiarities of growth of phosphors based on the single crystalline films of garnets by liquid phase epitaxy method. J. Surf. Investigation. X-ray, Synchrotron, and Neutron Tech. 5 83-90.

Zorenko, Yu., Gorbenko, V., Konstankevych, I., Voloshinovskii, A., Stryganyuk, C. Mikhailin, V., Kolobanov, V., Spassky, D., 2005. Single-crystalline films of Cedoped YAG and LuAG phosphors: advantages over bulk crystals analogues. J. Lumin. 114, 85-94.

Zorenko, Yu, 2006. Luminescence of $\mathrm{La}^{3+}$ and $\mathrm{Sc}^{3+}$ isoelectronic impurities in $\mathrm{Lu}_{3} \mathrm{Al}_{5} \mathrm{O}_{12}$ single crystalline films. Opt. Spectrosc. 100, 572-580.

Zorenko, Yu., Gorbenko, V., Mihokova, E., Nikl, M., Nejezchleb, K., Vedda, A. Kolobanov, V., Spassky, D., 2007a. Single crystalline film scintillators based on Ce- and Pr-doped aluminium garnets. Radiat. Meas. 142, 521-527.

Zorenko, Yu., Gorbenko, V., Konstankevych, I., Voznjak, T., Savchyn, V., Nikl, M., Mares, J.A., Nejezchleb, K., Mikhailin, V., Kolobanov, V., Spassky, D., 2007b. Peculiarities of luminescence and scintillation properties of YAP: Ce and LuAP: Ce single crystals and single crystalline films. Radiat. Meas. 42, 528-532.

Zorenko, Yu., Gorbenko, V., 2009. Growth and luminescent properties of single crystalline films of $\mathrm{RAlO}_{3}(\mathrm{R}=\mathrm{Lu}, \mathrm{Lu}-\mathrm{Y}, \mathrm{Y}, \mathrm{Tb})$ perovskites. Phys. Solid State 51 1800-1808.

Zorenko, Yu., Nikl, M., Mares, J.A., Gorbenko, V., Savchyn, V., Voznyak, T., Kucera, M. Beitlerova, A., Kucerkova, R., Fedorov, A., 2009a. The luminescent and scintillation properties of $\mathrm{YAlO}_{3}$ and $\mathrm{YAlO}_{3}$ :Ce single crystalline films grown by liquid phase epitaxy from BaO-based flux. Phys. Stat. Sol. (a), 1-7.

Zorenko, Yu., Mares, J.A., Kucerkova, R., Gorbenko, V., Savchyn, V., Voznyak, T. Nikl, M., Beitlerova, A., Jurek, K., 2009b. Optical, luminescence and scintillation characteristics of the Bi-doped LuAG and YAG single crystalline films. J. Phys. D: Appl. Phys. 42, 75501-75508. 